\title{
Sustainable, Smart and Safe Mobility at the Core of Sustainable Tourism in Six European Islands
}

\author{
Claudio Mantero
}

\begin{abstract}
Transport and tourism are rising economic sectors based on their mutual growth on reliable technological tools, affordable energy sources in relatively peaceful decades. This growing trend, faced along years of sudden slowdown caused mainly by the financial and health crisis; one of the most severe and recent episodes was the COVID-19 pandemic. The pandemic outbreak is representing a global turning point for both international markets of tourism and transport which can be addressed with innovative solutions looking to retake the growing trends. In such a changing framework CIVITAS DESTINATIONS European project addressed the main challenges of tourism and resident mobility at local (rural, urban area, large city) and regional levels, focusing on six European islands (Malta, Cyprus, Elba, Crete, Gran Canaria, Madeira) aiming to implement and evaluate 83 different sustainable mobility measures. The project proves to have a cumulative relevant impact on environmental indicators such as $\mathrm{CO}_{2}$ emission avoided, fossil fuel saved and energy saved. Additionally, the project findings focus on the quality of life and economic development to grant long-run environmental and financial sustainability of tourism and transport at the local and regional levels. The main aspects observed were related to public participation and governance models in touristic mobility integrated with the residents' needs, touristic mobility the island, role of technologies to focus on final user needs, growing trends of elder and disabled people, new integrated and innovative business in tourism and mobility markets, health at the core of future trends.
\end{abstract}

Keywords Sustainable mobility • Green tourism • Insular economies • COVID-19 $\cdot$ Tourism value chain 


\section{Introduction}

Transport and tourism sectors are strictly related and interconnected with mutual growth dynamics. Tourist trends raised continuously and steadily along the last decades, reflecting the demand's stimulation coupled with pushing economies (Cristea \& Mantero, 2020). Such trend drove the expansion of both tourism and transport markets which achieved higher figures and better performances year after year, as seen in Figs. 1 and 2.

The tourism sector has a key role at the European level, representing in 2019 near $10 \%$ of the total GDP. Focusing on the 6 countries that took part in the CIVITAS DESTINATIONS project through their insular regions, the figures of the Tourism sector for the country GPD is significant, varying from $11.6 \%$ in Malta to a maximum contribution of $22.66 \%$ in Cyprus (Pratt, 2015).

In CIVITAS DESTINATIONS, insular regions show a prominent role in the tourism industry compared to national economies. As possible to notice in Fig. 3, nearly $25 \%$ of the insular economies of Malta and Cyprus are related to the tourism sector, when on average national economies of the six sites rely on tourism only around 10\% (WTTC, 2020).

Since 1950, both sectors' economies started to grow and faced along the years four great recessions period related to two financial crises 2001-2002 and recently in 2007-2008, a health crisis of SARS pandemic in 2003 and COVID-19 in 2020. The last decline due to COVID-19 affected enormously tourism and transport markets with an estimated deterioration of international tourism demand of $60 \%$. Such a figure
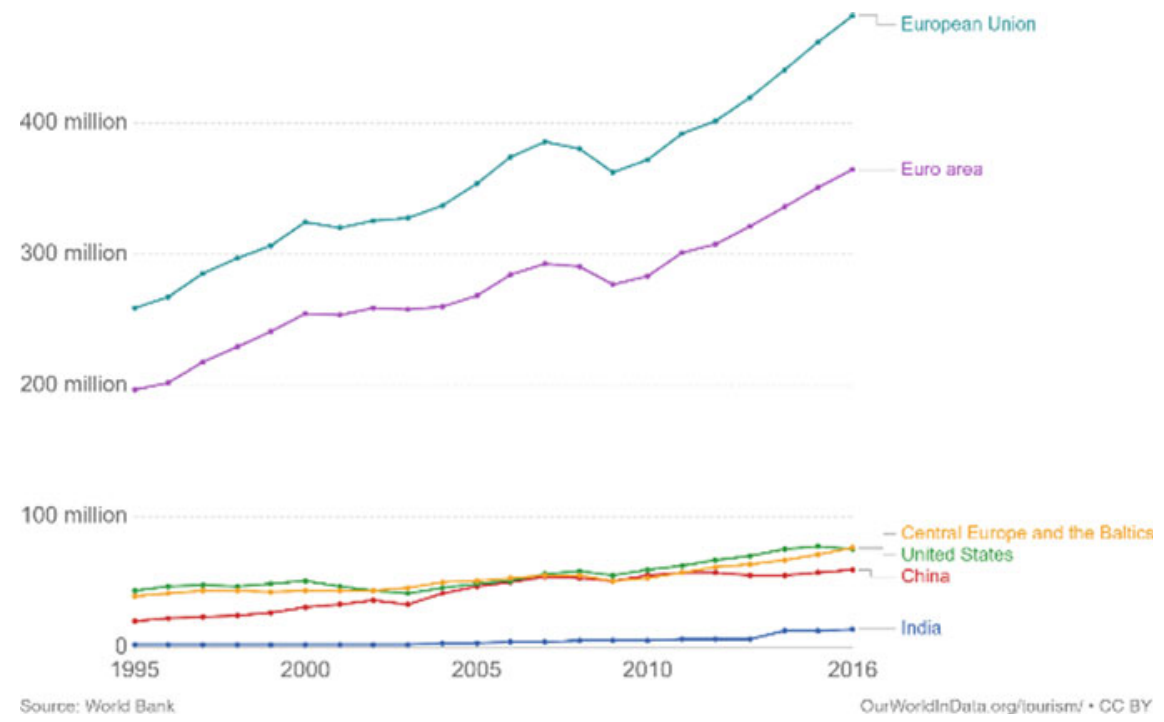

Fig. 1 International tourism demand — number of arrivals (Our world Data.org based on Word bank data) 


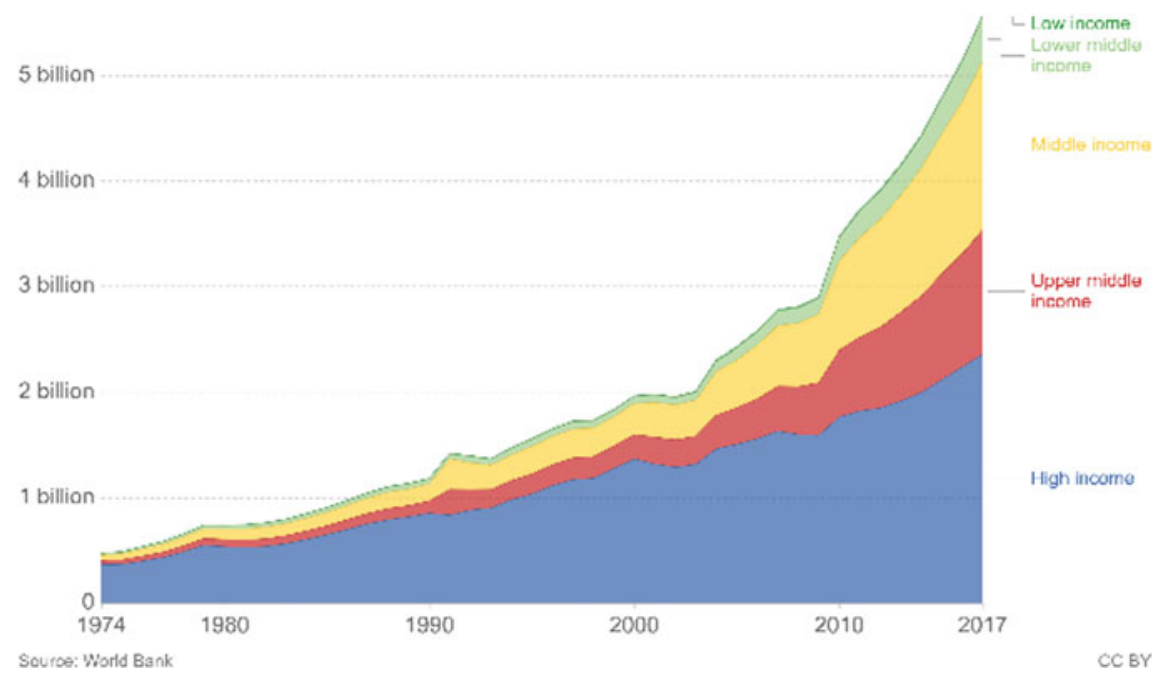

Fig. 2 Air transport demand—number of passengers (Our world Data.org based on Word bank data)

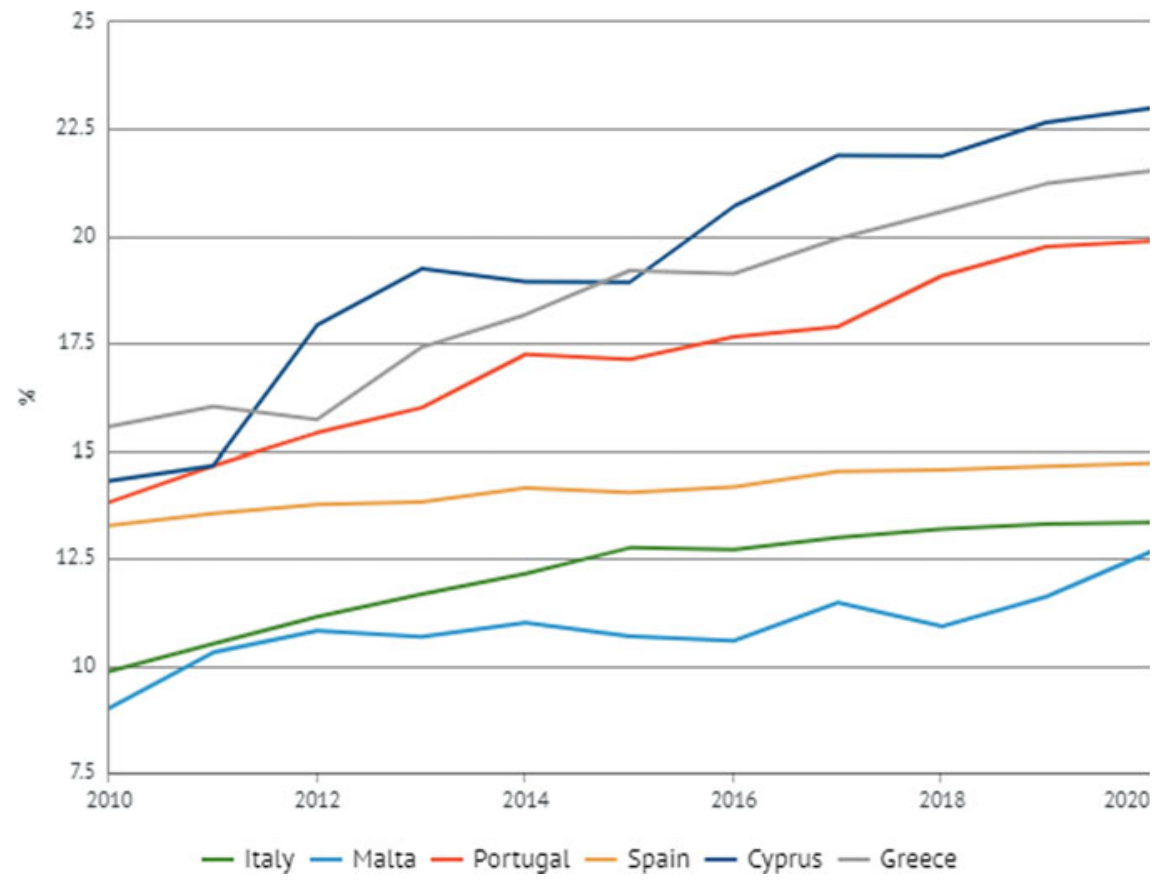

Fig. 3 Tourism sector weight in the GDP in DESTINATIONS countries (WTTC, 2020) 
was estimated to rise to $80 \%$ until December 2020 if the pandemic recovery will delay (OECD, 2020). An average decline of transport in urban areas during the lockdown reached $75 \%$ and stabilized during July 2020 between 20 and 50\%. ${ }^{1}$ Despite the COVID-19 demand and offer downfall, recovery for both markets to pre-crisis figures is not expected before 2022 (OECD, 2020; IATA, 2020; Higgins-Desbiolles, 2020).

Before the COVID-19 outbreak, the trends of both industries shaped relevant positive effects at the economic and social levels, creating employment and improving national and local economic development. Tourism and travel represented in 2019, $10.3 \%$ of the global GDP with 330 million jobs created across the world representing the sector growths more after ICT and financial sectors (WTTC, 2020). Together with great benefits, tourism and travel industries generate relevant external adverse effects at social and environmental levels affecting the quality of life of cities (Koens et al., 2018), especially during the peak seasons. In such a general growing trend, the total balance is in almost all cases highly positive with more total benefits than private and social costs (Biondo, 2012).

After the COVID-19 pandemic outbreak in February/March, both sectors of transport and tourism started to recover the demand's decrease in June 2020. However, this period was considered by all stakeholders the right time to reassess the actual business models and to improve outdated processes based on the obsolete prerequisite of the 'golden age of travel and tourism', to address new rising challenges in customers' demand and rising market.

A successful business model, underneath the golden age of travel and tourism (UNWTO, 2016), can be traced back to two mobility milestones that changed the mobility of people dramatically for short and long distances. Both milestones are related to mass transport technological solutions and large distribution with robust and virtually infinite business models based on affordable resources (energy, land, urban spaces and manpower) and peaceful decades.

Affordable transport is a consequence of the large distribution of private cars, changing people's approach to distances and accessibility, introducing and promoting new lifestyles, new concept of time, new social relationships, more new habits and behaviours in general (MIND SETS, 2017). Transport modes modified the concept itself of vacation which was associated to the large diffusion of the family car and the principle of maximum mobility independence with no consideration for environment, liveability and quality of life of the touristic destinations, especially for the residents. During the fifties, the vacation idea resulted as a natural consequence of the consolidated car lifestyle model, with city planning oriented to the car and the socio-economic status of a private vehicle. More recently, the jumbo jet made the world smaller by enabling people to travel further and at less cost. Low-cost airline companies made air travel affordable, affecting the tourism experience and vacation planning in itself. Finally, the internet, mobile apps and social media, sharing platforms changed the holiday value chain (ITC-UNWTO, 2015), and the phases that build the touristic experience, including preparation, vacation and return.

\footnotetext{
${ }^{1}$ Data collected from in CIVITAS DESTINATIONS sites using automatic traffic counting data systems.
} 
It is a fact that the constant rising trend of both industries was based on a blissful combination of affordable transport in mostly deregulated markets, incomes increasing, low cost of commodities and worldwide safe and secure travel conditions. In the light of a sudden global event such as COVID-19, both markets realize their urgent need to develop more resilient strategies to have the capacity to rethink the actual business model including innovative approaches to address the long-run human challenge of sustainable development defined globally by the UN sustainable development goals (Higgins-Desbiolles, 2020). Both tourism and mobility can recover from the recession. However, they must define common innovative long-run strategic development objectives, combining progressively radical game changers/innovations such as, new stricter environmental regulation, intensive digitalization, accessibility for elder and disable, integrated and multimodal transport modes for all (Mckinsey, 2020; Romão, 2020; Page, 2009).

\section{Methodology and Data Collection}

CIVITAS DESTINATIONS sustainable mobility project, which started in September 2016, was the perfect laboratory to study and test innovative solutions to attract tourists to use less pollutant transport services and to appraise, innovative technologies and business dynamics looking deeply at new interaction at the local level between Tourists and Residents. The project tested 83 different mobility measures divided into 6 clusters during 4 years in six European islands, addressing mutual empowerment aspects of tourism and mobility, focusing also on positive and negative interactions at the city level. During the implementation, both sectors showed relevant aggregate effects on the local economy, well-being and quality of life of both residents and tourists. Fig. 4 presents the relevant project data, main targets and the partners involved in CIVITAS DESTINATIONS.

Following the CIVITAS evaluation process (Dziekan et al., 2013) depicted in Fig. 5, local evaluation managers collected in each site ex ante and ex post relevant indicators to monitor the progress and impact of each mobility measure to verify the achievement of main pre-set outcome indicators. The evaluation process it's depicted in the following diagram of methodology.

Evaluation data set, collected at measure level, referred to Economy, Energy, Environment, Transport system and Society. In the project framework, it was possible to outline, at a macro level, three main clusters of measures: shared mobility and walking, clean vehicles and public transport and estimate the outcomes achieved. Tables 1, 2 and 3 present, respectively, for each cluster, relevant outcome indicators collected to assess key thematic areas in sustainable mobility.

Together with the quantitative evaluation, relevant qualitative information was collected and studied in specific qualitative process evaluation exercises focusing on hampering and enabling factors during the different measure implementation phases.

As a result, all insular sites showed clearly peculiar challenges in touristic mobility at destinations, such as the seasonality in managing transport services related to 


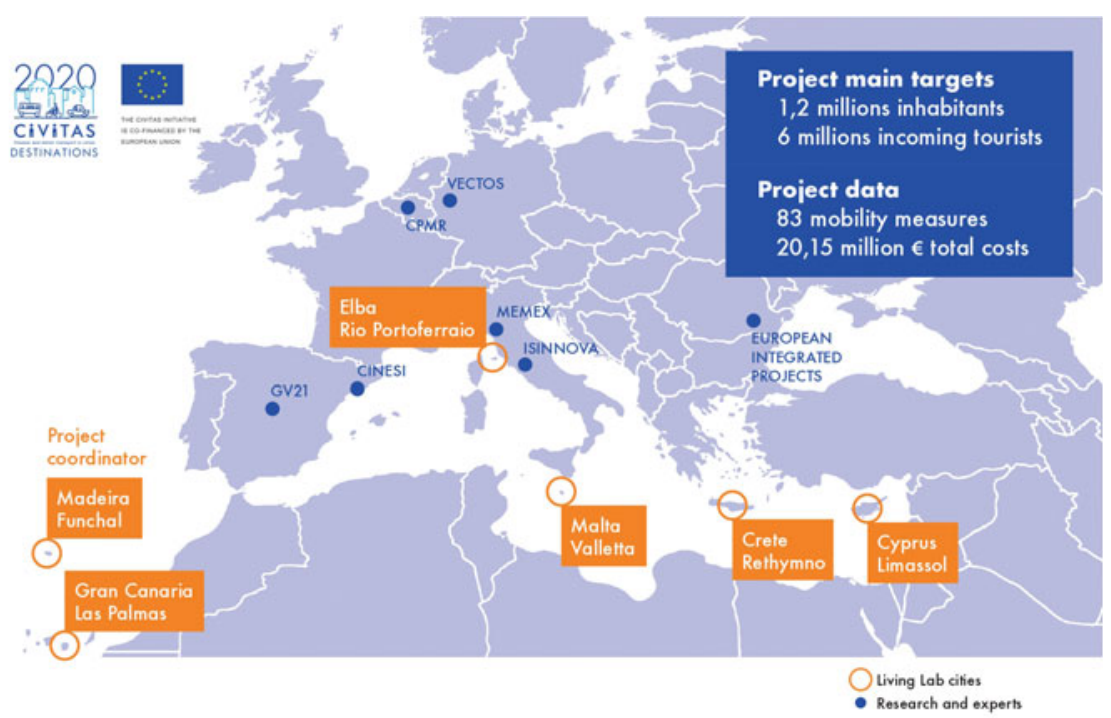

Fig. 4 The CIVITAS DESTINATIONS project sites, partners, main data and targets

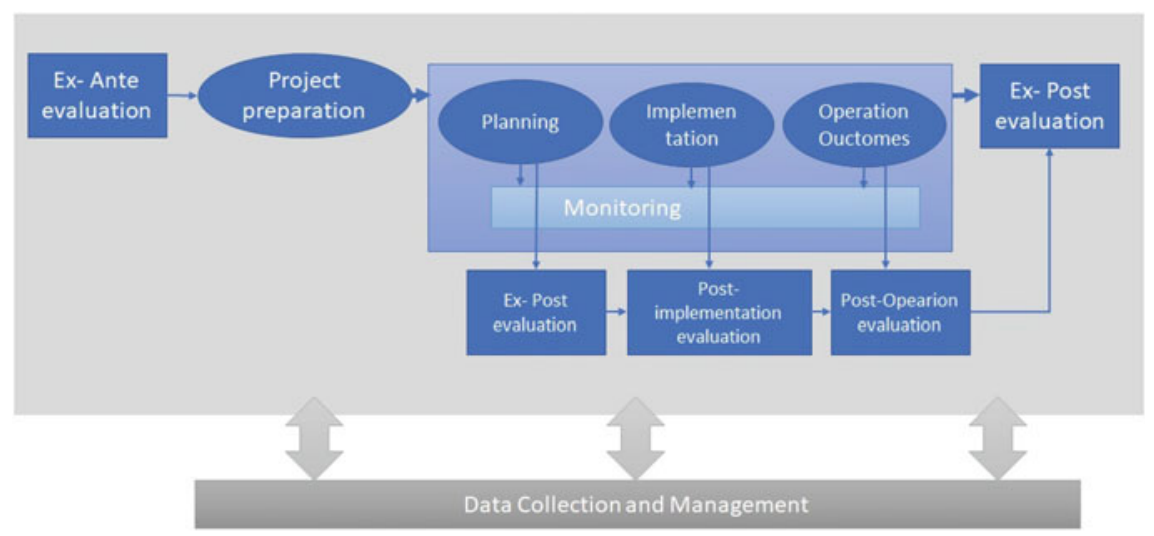

Ongoing reporting, reflection and learning

Fig. 5 Measure evaluation process applied in CIVITAS DESTINATIONS (Adaptation from Dziekan et al., 2013)

touristic demand, the growing trend of shared mobility resources together with walking options and lastly the growing spread of clean vehicle and public transport option (Gutiérrez \& Miravet, 2016; Mantero \& Gaudêncio, 2020).

At destination tourism sector interacts with transport services mostly as a neutral tool, one phase of the 'tourist value chain' process (ITC_-UNWTO, 2015). The basic 
Table 1 Project outcomes in shared mobility and walking cluster

\begin{tabular}{l|l|c}
\hline Cluster of measures & Indicator & Outcomes \\
\hline \multirow{2}{*}{$\begin{array}{l}\text { Las Palmas: LPA 4.1 Public e-bike } \\
\text { system }\end{array}$} & $\begin{array}{l}\text { Average number of additional users } \\
\text { Limassol: LIM 4.2 Expansion of public }\end{array}$ & 13,813 \\
\cline { 2 - 3 } bike-sharing system, including e-bikes & $\begin{array}{l}\text { Number of additional bikes (including } \\
\text { e-bikes) }\end{array}$ & 507 \\
\cline { 2 - 3 } & Additional km of cycle paths & 199 \\
\cline { 2 - 3 } & Fuel saved (litres/year) & 188,855 \\
\cline { 2 - 3 } & $\mathrm{CO}_{2}$ emissions avoided (ton/year) & 364 \\
\hline
\end{tabular}

Table 2 Project outcomes in clean vehicles cluster

\begin{tabular}{l|l|l}
\hline Cluster of measures & Indicator & Outcomes \\
\hline $\begin{array}{l}\text { Madeira: MAD 4.1 Promote the uptake } \\
\text { of clean vehicles by fleet operators }\end{array}$ & $\begin{array}{l}\text { Percentage of additional electric vehicles } \\
\text { Limassol: LIM 4.1 Electric car rental }\end{array}$ & $50 \%$ \\
\cline { 2 - 3 } $\begin{array}{l}\text { connecting Limassol with airport and } \\
\text { port }\end{array}$ & Energy saved (MWh) & 2,800 \\
\cline { 2 - 3 } $\begin{array}{l}\text { Limassol: LIM4.3 Promote the uptake of } \\
\text { electric vehicles, campaign on e-mobility }\end{array}$ & Reduction in operating costs (€/year) & 486,000 \\
\cline { 2 - 3 } $\begin{array}{l}\text { Rethymno: RETH 4.1 Uptake of electric } \\
\text { vehicles by fleet operators }\end{array}$ & Fuel saved (litres/year) & 228,000 \\
\cline { 2 - 3 } $\begin{array}{l}\text { Elba: ELB 4.5 eV legislation revision } \\
\text { and charging infrastructures }\end{array}$ & $\mathrm{CO}_{2}$ emissions avoided (ton/year) & 774 \\
\hline
\end{tabular}

Table 3 Project outcomes in public transport cluster

\begin{tabular}{l|l|l}
\hline Cluster of measures & Indicator & Outcomes \\
\hline $\begin{array}{l}\text { Las Palmas LPA 7.2-Hybrid buses in the } \\
\text { urban bus fleet }\end{array}$ & $\begin{array}{l}\text { Percentage of additional customers } \\
\text { (year) }\end{array}$ & $+10 \%$ \\
\cline { 2 - 3 } $\begin{array}{l}\text { Elba: ELB 7.1 Improve PT services for } \\
\text { tourists }\end{array}$ & Acceptance (\%) & $60 \%$ \\
\cline { 2 - 3 } $\begin{array}{l}\text { Limassol: LIM 7.1 Improvement of PT } \\
\text { routes, timetables, ticket procedure and } \\
\text { bike transportation on buses to make the } \\
\text { transport more attractive }\end{array}$ & Fuel saved (litres/year) & 10,200 \\
\cline { 2 - 3 } $\begin{array}{l}\text { Malta: MAL 7.1 Integration of ferries into } \\
\text { the Public Transport }\end{array}$ & & 162 \\
\hline
\end{tabular}

role of transport is to connect places and experiences to the tourists and in extreme and rare cases it can represent in itself the touristic experience such as toboggan as in Madeira Island, old vintage busses as the case of Malta or vintage trains (Lumsdon $\&$ Page, 2004). On the other side, transport sector developed during the last decade's specialized approach to tourism mobility demand with dedicated services such, tour operator airlines, charted busses, sightseen busses, car rental and touristic mobility options such tuk-tuk and other similar alternatives. Such touristic transport business 
can be associated with the blooming of new companies providing touristic mobility services providing innovative transport solution with exotic transport modes such rickshaw, tricycles, tuk-tuks, bike beers or in other cases such specialized touristic mobility services are a consequence of the vertical integration of tourism actors which expand their business sector including transport activities or internalizing transport companies (Grossman \& Hart, 1986).

At a city level, it's clear that urban transport operators and services are mostly designed and planned according to the residents' needs except for specific lines or connections that have a specific touristic interest. Public transport, and the other transport schemes (i.e. DRT, ride-sharing) usually don't address specifically tourists as a core target passenger group for lacking data/information collection and capability/tool for monitoring the dynamic variations of the needs/demand. The 'simple' and common action carried out is the updating of the service programme on the basis of the season and main event. In the case of the mobility plan and evaluation process, usually, transport stakeholders collect limited information about tourist's mobility patterns with limited chance to define proper information and commercial strategies to tailor-made their services to touristic needs and attract more customers to sustainable transport option at touristic destinations.

\section{Results and Discussion}

In CIVITAS DESTINATIONS after the implementation of 83 urban and regional mobility measures in touristic destinations sites, with specific attention to tourist needs, mobility and tourism stakeholders have been following and responding to common main trends along with the project development, testing innovative solution and learning relevant lessons. ${ }^{2}$

\subsection{Relevance of Decision Process and Data Collection to Act in Touristic Mobility}

Stakeholder involvement and participated decision is essential in both touristic and mobility sectors to grant the acceptance of people and stakeholders (Kernel, 2005). Mutual exchange of information and dataset between both sectors is essential to improve the decision process at the city level reducing information overlapping and can bring to the definition of informed and agreed plan to address common issues affecting tourism and mobility such as traffic congestion. Tourism actors' contributions are essential to define a comprehensive mobility strategy at the urban level.

\footnotetext{
${ }^{2}$ Each measure has been duly assessed with ex ante and ex post evaluation methodology finish up a measure evaluation report (MER) document. All MERs will be release in final version on first semester 2021.
} 


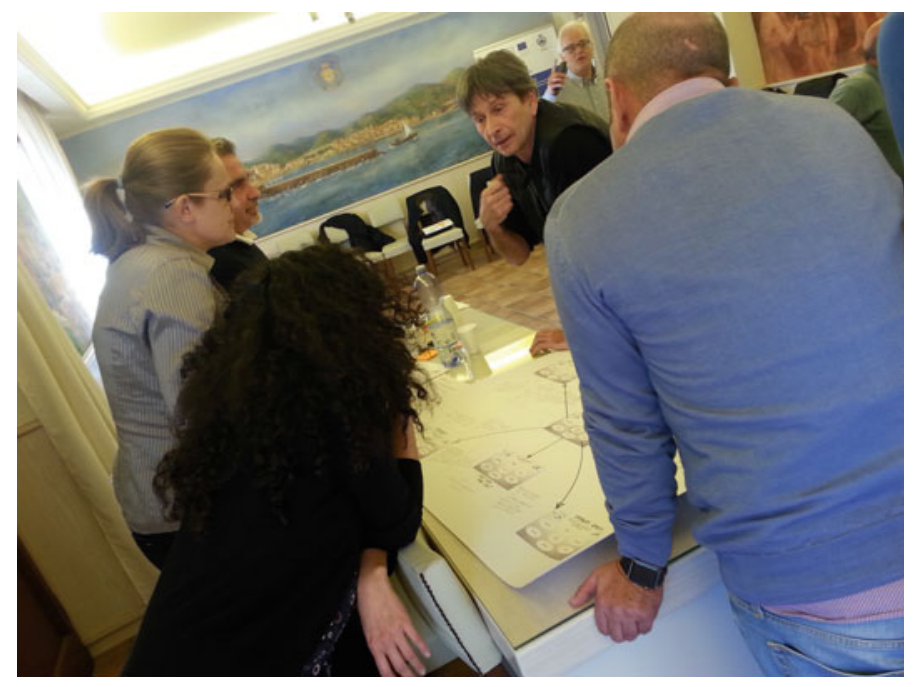

Fig. 6 Participatory in Portoferraio involving mobility and tourism stakeholders

As shown in Fig. 6, in Portoferraio, specific co-creation sessions brought relevant contributions to shape mobility and also to define long-run urban mobility strategy.

At the city level, transport and tourism sectors must share data to avoid the double work, to take advantage of synergies, to understand tourist's mobility patterns and to act in the more congested areas with specific measures. Transport technician's knowledge about touristic mobility is usually limited, however, this information is essential to define clear mobility plans at the urban level, for medium-long-run improvement of the quality of life of both residents and visitors.

\subsection{Tourists at Destinations Prefer to Walk}

In each site, it was applied a questionnaire to know tourist mobility to a representative sample of at least 400 tourists leaving the islands after the vacation experience. The data presented in Fig. 7 were collected at airports, ports and main touristic spots and are relevant to understand touristic mobility habits at a quantitative and qualitative levels.

Tourist with pre-booked transport mode options in the 6 site represents the great majority of tourists arrived at the destinations (48\%). The transport choice is mainly oriented to cars, especially in places where airports are far from the main cities and public transport services are scarce or not integrated. Nevertheless, during the stay, an average of $33 \%$ of tourists, prefer to walk to move around and visit the destination. 


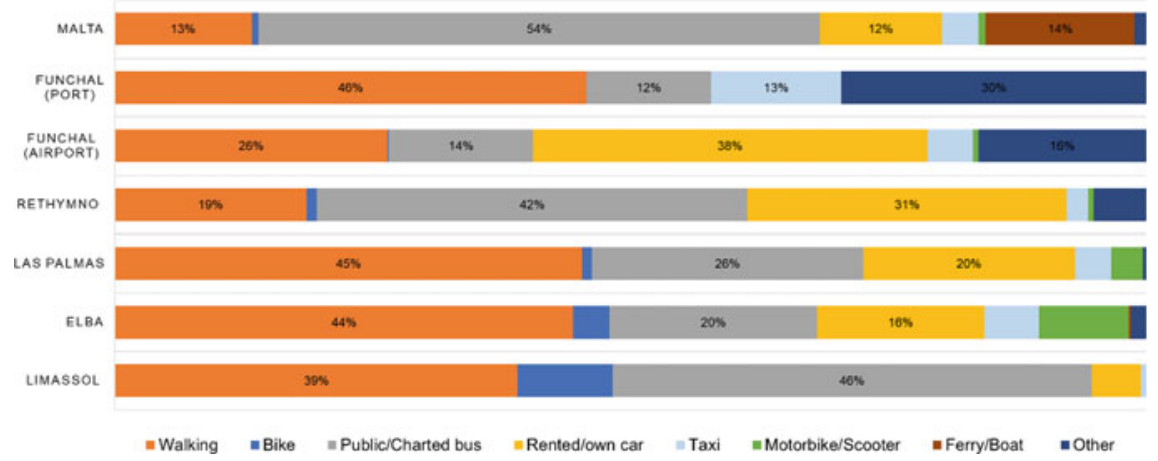

Fig. 7 Touristic transport modal share in each DESTINATIONS site

\subsection{Role of Technological Tools to Simplify User Experience and to Improve Decision-Making}

CIVITAS DESTINATIONS project assessed carefully technological tools involved in mobility planning and information in six cities, defining three different ITS categories: traffic management, public transport service operation, and mobility platforms. The main challenges observed in each site were the lack of integrated, shared, standardized information databases about mobility and tourism. Together with this fragmented data precondition, technological solutions implemented by public and private mobility actors are assorted, tailor-made and in many cases difficult to be integrated into the perspective of the end-user (tourist or resident). Such characteristics made local ITS solutions in small and medium cities incomplete and not integrated, affecting negatively the decision process in mobility and tourism markets. Such market failure brought to evident a lack of efficiency and effectiveness in the overall mobility offer (Ambrosino et al., 2016; Schwalbe, 1999).

Mobility as a service platform represents a customer-oriented conceptual model to allow users to compare and purchase the best mobility solution via a mobile app with an intuitive interface (Zijlstra et al., 2020). To address final users' needs, a relevant technological key feature is a multi-service sharing/booking intuitive platform which combines mobility and transport solutions with touristic services in simple information and purchase apps. Such platforms must be designed keeping in mind touristic/mobility customer needs, making easy and intuitive the selection process, the booking and the payment itself. Multiservice platforms (MP) as described in Fig. 8, consider tourists at the core of the services adapting and combining different complimentary services according to the final user perspective. In the case of Elba, the Mobility Sharing Agency addressed such technological challenges and design and implement a sharing mobility platform to provide information, allow booking, service payment, data quality assessment of services. The large-scale test was delayed due to the COVID-19, in any case, the launch and implementation were held on June 2020 and extensive evaluation of the platform performances was delayed at 2021. 


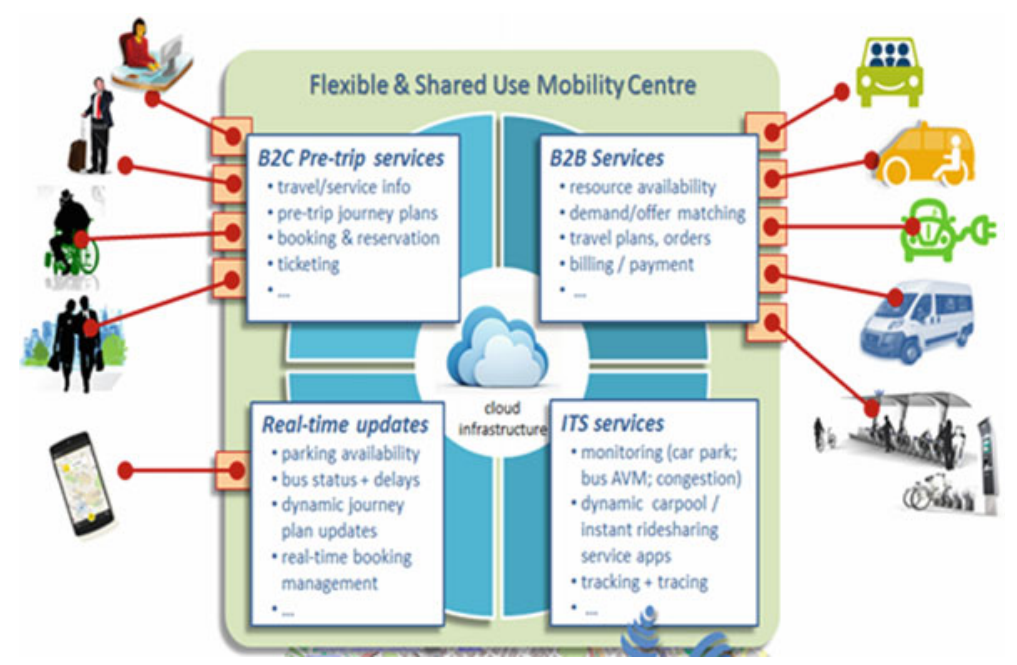

Fig. 8 The Shared Mobility Coordination Agency as kernel of Mobility as a Service (MaaS) transport offer system (Ambrosino, 2018)

\subsection{Elder and Disabled People Growing 'Core Customer'}

The baby boomer generation is one of the rising market segments in tourism. In 2017, in the EU, people with more than 55 years total up $38.5 \%$ of the total expenditure on tourist trips of at least one night. Such average data have relevant peaks considering the main outbound touristic markets of France (42.7\%) and Germany (44.0\%) (EUROSTAT, 2019). Together with the growing trend, disabled people's travel demand is also continuously growing in the EU with great potential for market specialization and innovation (EC, 2014). Considering such figures and trends accessibility and specific requirements dedicated to elder and disabled people are the core issues for the future of European tourism and sustainable mobility (EUROSTAT, 2019; UN, 2019). This trend represents not only an improvement challenge for already settled businesses and services but also an opportunity for new businesses or innovative tailored, on-demand services. Relevant measures were implemented in Funchal, Limassol, Rethymno and Portoferraio to improve accessibility for disable and visually and hearing-impaired people concerning walking facilities, public transport, informative tools, lighting systems, beaches access, transport hubs and figures were studied in Madeira in what regards public transport service adaptation to tourists needs in the specific case of elder and disabled people. Figure 9 depicts a measure implemented in Portoferraio to improve the accessibility of elder and disable tourists and residents. 
Fig. 9 Accessibility measure implemented in Portoferraio to increase accessibility and reduce traffic speed

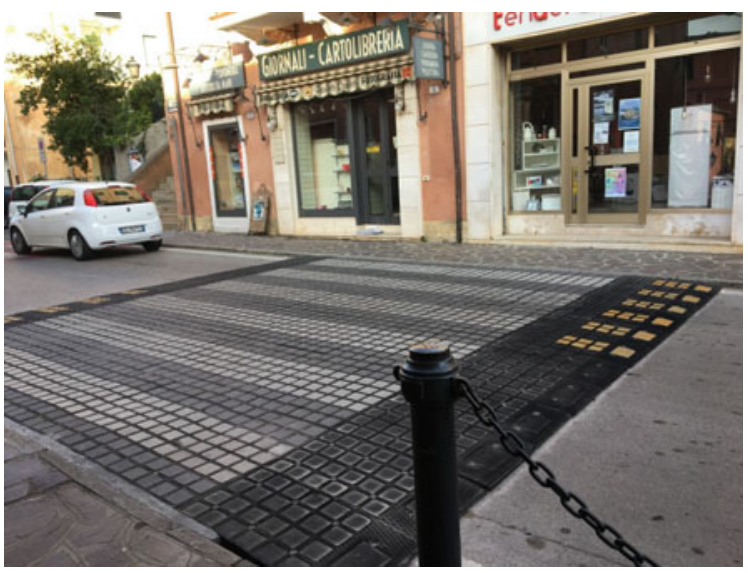

\subsection{Mobility Franchises and Need for Tailor-Made Adaptation Case by Case}

To have successful sustainable mobility systems, mobility franchises must be adapted to the local needs, habits and touristic patterns with relevant tailor-made interventions. Local businesses and local entrepreneurs are fully aware of local economic specifications and they play a key role to start local integrated services more attentive to unique tourist and resident needs. Such integrated and tailor-made solutions can be also upscaled in other regions with similar specifications and characteristics. Expressive findings of such a positive approach were evaluated in Las Palmas, Rethymno and Limassol for the bike-sharing systems.

\subsection{Vertical and Horizontal Integration in Touristic Value Chain Market, Innovative Business Models and Market Regulation Challenges}

In both sectors, and in recent years, it was verified a progressive improvement and transformation of the touristic value chain (ITC-UNWTO, 2015), and related supply chain. Mobility operators are expanding their market at the transport level merging services and providers. Such integration trend is not only visible in the same industry but also in complementary touristic industries such as leisure, travel agencies and accommodation services. Tourism operators, in a balanced way, are approaching transport services and providers, seeking integration opportunities, acting with an identical complementary aspiration in the mobility market. Such a trend in transport and tourism markets was proved in the six sites acting in the same industry or in other complementary industries in the tourism value chain process (Lafferty \& Van 


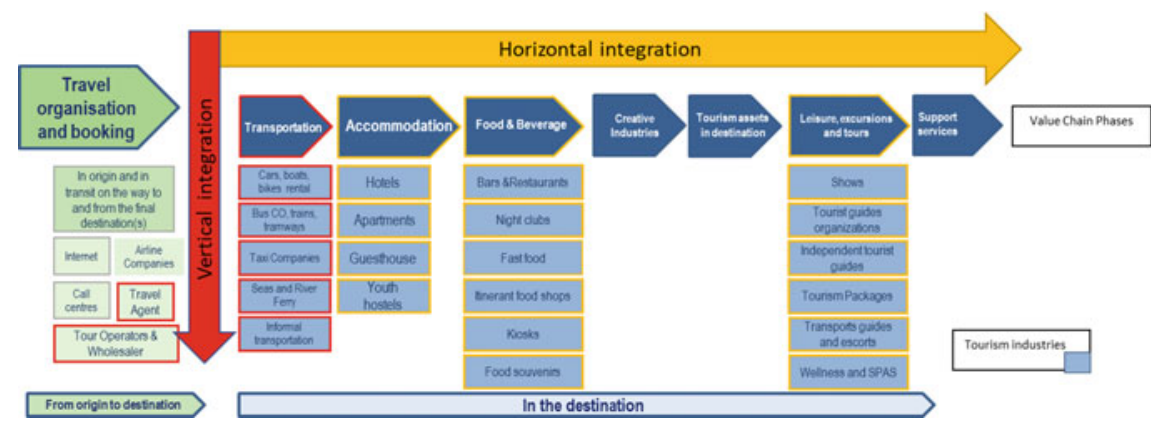

Fig. 10 Tourism value chain adaptation (ITC \& UNWTO, 2015) to highlight the horizontal and vertical integration trends in mobility and tourism industries

Fossen, 2001). In the following figure, using the main reference of touristic value chain sequence is possible to identify the horizontal and vertical integration lines in Transport and Mobility sector at touristic destinations. In Fig. 10, vertical integration of different mobility operators in the same transport industry is depicted in red, while in yellow are highlighted the possible and growing integration of transport services with complementary touristic products/services such as tour operators, travel agencies, tourist guides, tourist attraction and others.

This situation leads to peculiar risks and opportunities. The main risks are related to the possible reduction of quality service in 'non-core' markets with fewer skills and experience and a potential oversupply product diversification in some cases cannot find enough demand to completely absorb the offer, with potential market saturation issue and the resulting need for better and improved regulation, to grant the minimum quality standards for residents and tourists. As a natural consequence of such integration, both tourist and mobility actors are keener and keener in working in wider markets involving complementary services or complementary industries to provide more sustainable services, not only at the touristic destination but also at the origin (Álvarez-Albelo \& Hernández-Martín, 2012).

All in all, at the city level, touristic transport offer regulation is a key issue to avoid service overlapping and excessive congestion of main touristic areas and services providers. A clear and conservative market regulation of touristic mobility services is essential to drive a well-planned integration between touristic mobility and resident mobility needs. Market access, integration requirements and minimum service quality standards are key aspects that need to be studied and analysed at the local level with great attention, to speed up economic development with limited negative externalities. 


\subsection{Transport as Part of Touristic Experience}

Transport service is mainly considered by the tourism sector as a way to deliver the touristic experience (Lumsdon \& Page, 2004). The great majority of transport operators at the urban and regional levels are focused to provide high-level mobility services with limited touristic add value. This propensity is progressively changing and the mobility sector, at city and regional levels, started to be part of the touristic experience bringing enriching experiences to the tourists by itself or related to other services or products via the cross-selling or cross-discount tools (Ge, 2009). In this respect, relevant experiences about this successful strategy were tested in Madeira and Las Palmas de Gran Canaria with specific cross-selling/discount initiatives that combine transport and tourism services. In Madeira, Public Transport Friend initiative collect 27 touristic related shops and services providers which started to deliver cross discount to public transport passengers with a relevant increase of passengers within the tourism segment. In Las Palmas, a green loyalty system encourage citizens and tourists to adopt more sustainable lifestyle patterns by providing tangible economic rewards (points) using public transport. The points collected can be used to purchase products or services in shops, museums or theatres. In Fig. 11 is represented a schematic of the different measures implemented and tested in CIVITAS DESTINATIONS to increase the intrinsic value of transport as a tourism experience, moving from Transport as mere Utility to Transport as a Tourism experience.

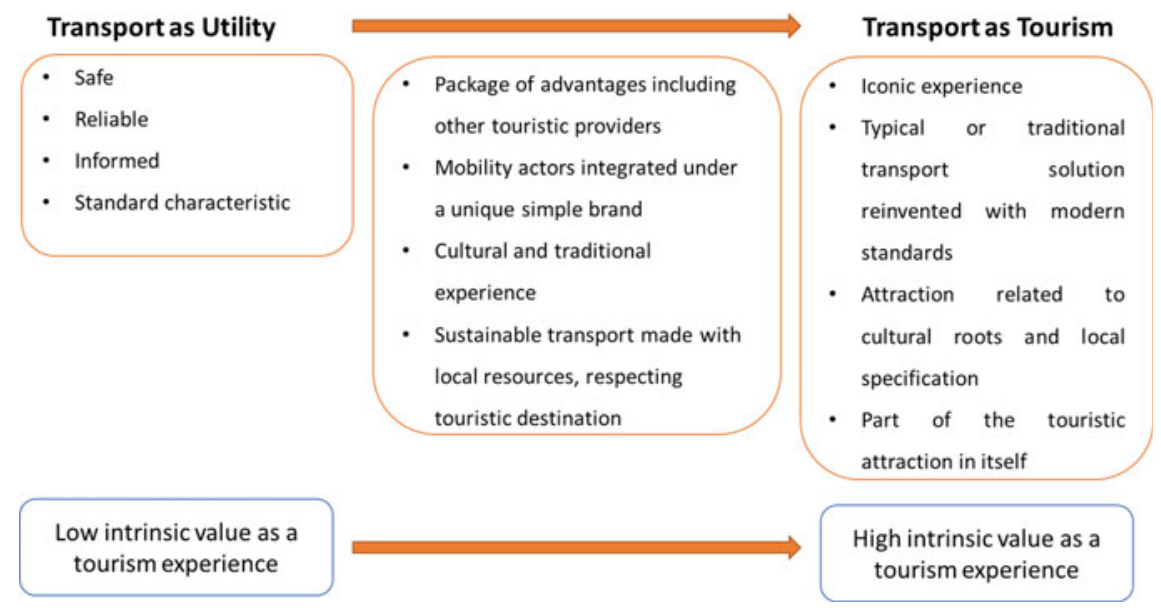

Fig. 11 Adaptation from Tourism and Transport, p. 7, Lumsdon and Page (2004) to present the measures tested in the sites that increase the intrinsic value of transport as a touristic experience 


\subsection{Health as a Cornerstone to Design Future Tourism and Mobility Services}

According to EUROSTAT, data health issues represent one of the main reasons people aged 65 years and more in the EU do not travel (EUROSTAT, 2019). Such figures were affected in the light of the recent pandemic of COVID-19. The health aspect since March 2020 will be more and more at the core of the service supply design, and it is considered by tourism providers and potential customers a relevant issue to address with specific resources and skills. It's a fact that social distance, protection and hygiene will be considered during the pandemic period as part of the minimum quality standard for sustainable mobility services such as public transport and sharing services. Such measures were also been enforced in the sites with specific regulations tools to support health measures (Fig. 12) and to promote touristic destinations as safe and clean places via certifications and seal of disinfection.

Fig. 12 Information and communication campaigns examples in Madeira

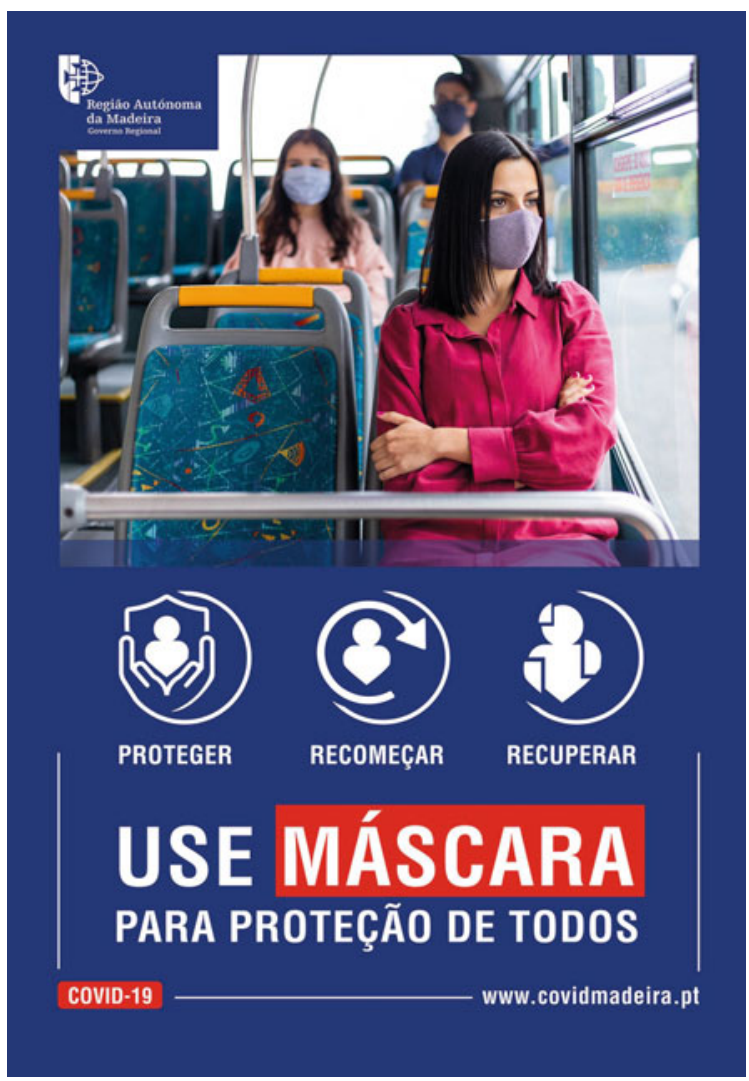




\section{Conclusions}

Tourism and travel are key industries that globally represent in 2019, $10.3 \%$ of the total world GDP (WTTC, 2020). In insular contexts the role of both economies is pertinent (PRATT, 2015), in particular in the CIVITAS DESTINATIONS insular regions Tourism alone represents a core economy, reaching approximately $25 \%$ of the total island GDP (WTTC, World Travel and Tourism Council Data).

Considering the relevance of both sectors at the insular level, in the light of the recent challenges of COVID-19 which affected dramatically global tourism and travel demand, CIVITAS DESTINATIONS analyse the fundamentals of both economies, the interconnection of the industries and found innovative solutions to drive the upraise of the global demand of travel and tourism. In the six implementation sites, the project partners had the chance to develop and test during 4 years project effective measures to attract tourists to sustainable transport modes testing new business models, implementing alternative governance/regulation models and piloting integrated solutions. The main trends/main lessons about touristic mobility at destinations faced in the previous sections, can be summarised as the following ones: relevance of decision process and data collection to act in touristic mobility; tourists at destinations prefer to walk to discover places, the role of technological tools to simplify user experience to improve decision-making, elder and disable people growing 'core customer'; shared asset mobility franchises and need for tailor-made adaptation case by case; vertical and horizontal integration in touristic value chain market, innovative business models and market regulation challenges; transport as part of the touristic experience; health as the cornerstone to design tourism and mobility services.

The lessons and rising trends in tourism and transport depicted in this chapter want to contribute actively to feed the undergoing discussion about the future of urban mobility and tourism and the tourism value of chain addressing the challenge of seasonality and sustainable management of local resources to drive the innovation towards a more sustainable future for both industries. The measures tested in CIVITAS DESTINATIONS represent an effective way to address the challenges of sustainable mobility and tourism in the long run, addressing today's challenge of COVID-19 under the UN Goals references, bringing both sectors directly in a new 'silver age of tourism and transport' (EUROSTAT, 2019).

\section{References}

Álvarez-Albelo, C., \& Hernández-Martín, R. (2012). Congestion and coordination problems in a tourism economy. Tourism Economics, 18(4), 691-710. https://doi.org/10.5367/te.2012.0136

Ambrosino, G., Nelson, J., \& Gini, S. (2016). The pivotal role of public transport in smart mobility: The concept of flexible and shared mobility centre towards MaaS. In M. Schrenk, V. V. Popovich, P. Zeile, P. Elisei, \& C. Beyer (Eds.), REAL CORP 2016 Proceedings/Tagungsband, 22-24 June 2016. http://www.corp.at. ISBN 978-3-9504173-0-2 (CD), 978-3-9504173-1-9 (print). 
Ambrosino, G. (2018). Shared use mobility agency in Elba island: From the concept to the IT Platform. EU CIVITAS DESTINATIONS project. Retrieved September 07, 2020, from http:// www.memexitaly.it/wp-content/uploads/2018/09/Booklet_Shared-Use-Mobility-Agency.pdf

Biondo, A. E. (2012). Tourism and sustainability: The positive externality. International Journal of Sustainable Economy, 4, 155-166.

Cristea, L., \& Mantero, C. (2020, September). Legacy document. Internal working document in CIVITAS DESTINATIONS project.

Dziekan, E., Riedel, V., Müller, S., Abraham, A., Kettner, S., \& Daubitz, S. (2013). Evaluation matters, a practitioners' guide to sound evaluation for urban mobility measures. Waxmann. Retrieved September 07, 2020, from https://www.researchgate.net/publication/304538182_Eva luation_matters_A_practitioners'_guide_to_sound_evaluation_for_urban_mobility_measures

European Commission. (2014). Economic impact and travel patterns of accessible tourism in Europe-Final report 2014. Retrieved September 07, 2020, from http://ec.europa.eu/DocsRoom/ documents/7221/attachments/1/translations/en/renditions/native

Eurostat. (2019). Ageing Europe, looking at the lives of older people in the EU (2019 ed.).

Ge, Y. (2009). The Sage handbook of tourism studies (T. Jamal \& M. Robinson, Eds., Chapter: 21). Sage Publications.

Grossman, S. J., \& Hart, O. D. (1986). The costs and benefits of ownership: A theory of vertical and lateral integration. Journal of Political Economy, 94(4), 691-719. https://doi.org/10.1086/ 261404. ISSN 0022-3808.

Gutiérrez, A., \& Miravet, D. (2016). The determinants of tourist use of public transport at the destination in sustainability.

Higgins-Desbiolles, F. (2020). The "war over tourism": Challenges to sustainable tourism in the tourism academy after COVID-19. Journal of Sustainable Tourism.

International Air Transport Association (IATA). (2020). COVID-19 puts over half of 2020 passenger revenues at risk, 14 April 2020. Retrieved September 07, 2020, from https://www.iata.org/en/pre ssroom/pr/2020-04-14-01/

International Trade Centre (ITC), \& World Tourism Organization (UNWTO). (2015). Tourism and trade: A global agenda for sustainable development. Geneva.

Kernel, P. (2005). Creating and implementing a model for sustainable development in tourism enterprises. Journal of Cleaner Production, 13, 151-164.

Koens, K., Postma, A., \& Papp, B. (2018). Is overtourism overused? Understanding the impact of tourism in a city context. November 2018 in Sustainability (ISSN 2071-1050; CODEN: SUSTDE).

Lafferty, G., \& Van Fossen, A. (2001). Integrating the tourism industry: Problems and strategies. Tourism Management, 22(1), 11-19.

Lumsdon, L., \& Page, S. J. (Eds.). (2004). Tourism and transport: Issues and agenda for the new millennium. Elsevier.

Mantero, C., \& Gaudêncio. (2020). Shaping mobility value chain in Madeira-The challenges of tourist mobility. Traficom research reports 7/2020. Retrieved September 07, 2020, from https://www.traficom.fi/sites/default/files/media/publication/TRA2020-Book-of-AbstractTraficom-research-publication.pdf

Mckinsey \& Company. (2020). The impact of COVID-19 on future mobility solutions.

MIND SETS. (2017). EU cofunded project, Contract No. 640401, D. 3.2 Future mobility challenges and D 4.1 New knowledge on mobility.

Our world Data.org based on Word bank data. Retrieved September 07, 2020, from https://ourwor ldindata.org/tourism

Organisation for Economic Cooperation and Development (OECD). (2020). Tourism Policy response to the coronavirus (COVID-19)—Updated to 2nd June 2020. Retrieved September 07, 2020, from https:/www.oecd.org/coronavirus/policy-responses/tourism-policy-responses-tothe-coronavirus-covid-19-6466aa20/

Page, S. J. (2009). Transport and tourism: Global perspectives (3rd ed.). Pearson Education 
Pratt, S. (2015). The economic impact of tourism in Small Island Developing States. Annals of Tourism Research, 52, 148-160.

Romão, J. (2020). Smart specialization and tourism competitiveness. Sustainability, 12(14). Retrieved September 07, 2020, from https://doi.org/10.3390/su12145765

Schwalbe, U. (1999). The core of economies with asymmetric information. Springer

United Nation World Tourism Organization (UNWTO). (2016). International tourist arrivals up 4\% reach a record 1.2 billion in 2015. Press release 16008. Retrieved September 07, 2020, from https://www.unwto.org/archive/global/press-release/2016-01-18/internationaltourist-arrivals-4-reach-record-12-billion-2015

United Nations. (UN). (2019). Department of Economic and Social Affairs Population Division, World Population Ageing, New York, 2019.

World Travel and Tourism Council Data. (WTTC). (2020). Retrieved September 07, 2020, from https://wttc.org/Research/Economic-Impact

World Travel \& tourism Council (WTTC). (2020). Global economic impact \& trends 2020_June 2020. Retrieved September 07, 2020, from https://wttc.org/Research/Economic-Impact

Zijlstra, T., Durand, A., Hoogendoorn-Lanser, S., \& Harms, L. (2020). Early adopters of mobilityas-a-service in the Netherlands. Transport Policy, 97, 197-209.

Open Access This chapter is licensed under the terms of the Creative Commons Attribution 4.0 International License (http://creativecommons.org/licenses/by/4.0/), which permits use, sharing, adaptation, distribution and reproduction in any medium or format, as long as you give appropriate credit to the original author(s) and the source, provide a link to the Creative Commons license and indicate if changes were made.

The images or other third party material in this chapter are included in the chapter's Creative Commons license, unless indicated otherwise in a credit line to the material. If material is not included in the chapter's Creative Commons license and your intended use is not permitted by statutory regulation or exceeds the permitted use, you will need to obtain permission directly from the copyright holder.

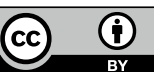

